\title{
SHOCK MITIGATION FOR ELECTRONIC BOARDS WITHIN A PROJECTILE
}

\author{
D. S. SOMASUNDARAM, M. B. TRABIA, B. O'TOOLE \& Q. LIU \\ Department of Mechanical Engineering, University of Nevada, Las Vegas, Las Vegas, Nevada, USA.
}

\begin{abstract}
Electronic components, which are widely used in modern projectiles, are subjected to high acceleration during launch. These accelerations may result in failure of the components, which affects the performance of the projectile. The objective of this research is to better understand how shocks are transmitted to electronic boards within a projectile and also to investigate ways of mitigating these shocks. To achieve these goals, a projectile prototype, composed of threaded components, was created. The effect of the tightening preload torque on the accelerations and the frequencies of the components on an electronic board were explored. An approach to mitigate transmitted accelerations to the board using a polyurethane rubber mount is presented. Suggestions for ensuring an accurate finite element model of the experimental setup are included.
\end{abstract}

Keywords: Bolted joints, finite element analysis, impact analysis, projectile electronics, shock mitigation.

\section{INTRODUCTION}

The past 20 years has witnessed several efforts to develop 'smart artillery' munitions that contain sophisticated embedded electronic components. These munitions operate in extreme conditions, including temperature ranging from $-60^{\circ} \mathrm{F}$ to $160^{\circ} \mathrm{F}$, quasi-static loads in excess of $15,000 \mathrm{~g}$ 's, and transient loads up to 50,000 g's [1]. These projectiles also are subjected to off-axis loads from impacts with gun tube walls, caused by balloting [2]. This harsh environment negatively affects the survivability of these electronic components. The complex interaction between the projectile and the embedded electronic components makes it difficult to conduct experiments or finite element analysis (FEA) to obtain a quick and reliable understanding of the problems associated with the survivability of the electronic components within a projectile.

The following is a brief overview of some of the research conducted in this area. Heaslip and Punch [3] concluded that a large percentage of portable electronic products fail due to impact and shock. They also illustrated that high-level strains occur at clamped edges of electronic boards. Hopkins and Wilkerson [4] examined a projectile launch event with the objective of reducing the dynamic response of the embedded electronic systems during firing. Hollis [5] developed a two-dimensional quasi-static model of a projectile. The projectile was redesigned to reduce stresses during launch. Cordes et al. [2] presented a simplified model of a projectile using shell elements; natural frequency effects were considered. Lim and Low [6] examined the drop impact response of portable electronic products at different impact orientation and drop heights. Karppinen et al. [7] studied the effects of drop tests on unsupported electronic products. They compared the results with those of a 4-point board level drop test. Suhir [8] evaluated the nonlinear dynamic response of a flexible printed circuit board (PCB) to shock loads acting on its support contour. He proposed formulas that could be helpful when choosing the appropriate PCB type and dimensions as well as the most appropriate layout of the electronic components on the board.

Alsaleem et al. [9] studied the response of Micro-Electrical-Mechanical Systems (MEMS) devices under shock loads, including the effect of PCB motion using a two-degree-of-freedom 
model. Chakka et al. [10] developed a finite element model that described the interaction of a typical projectile having an electronic package with a gun barrel during launch. A parametric study was included on the effects of varying the thickness of the composite supporting plate and the fiber volume fraction on the transmitted accelerations. Amy et al. [11] reviewed and compared methods for predicting the reliability of electronic equipment. Cordes et al. [12] compared accelerations measured during different types of ballistic tests to determine if the tests were in the same statistical family. Comparisons of g-forces were also made using shock response spectra. The shock response results indicated that the damage potential was greatest for the rail gun tests, which is consistent with an increased rate of failure of electronic components. Cui et al. [13] presented a sensitivity analysis for a typical MEMS package to relate the dependence of the maximum stress of the solder joint to the design parameters and the properties of the PCB and solder.

The problem of understanding the behavior of electronic components under shock loading is further complicated by the fact that different projectile parts are threaded. Little work has been published on shock transmission through bolted structures. The tightening torque, applied to these threaded parts, affects the transmitted forces to electronic components. This complex behavior of threaded components plays an important role in the dynamic characterization of structures. This complex behavior can be the effect of slip in the contact area around the bolted joints. Eskandarian et al. [14] developed a detailed finite element model to establish an understanding of the slip-stick mechanism in the contact areas of the bolted joints.

Bolted or riveted joints can be an important source of damping in structures because of the friction in the contact area. Kess et al. [15] constructed nonlinear finite element models to simulate the energy dissipation through joints. Lobitz et al. [16] investigated energy dissipation due to micro-slip in bolted joints, and developed a detailed nonlinear finite element model for this purpose. Gaul et al. [17] studied the nonlinear transfer behavior of the frictional interfaces that provide dominant damping mechanism in jointed structures. This plays an important role in the vibration properties of the structure. Park et al. [18] investigated the energy dissipation capacity and effects of the local deformations of friction-type reinforcing members and bolted slip joint slips. Wu [19] proposed a finite element method that can be applied to estimate the complex nonlinear behavior of bolted flange type connections subjected to bending loads.

Few researchers have considered the effects of threading and tightening on the transmission of dynamic loads. For example, Augustaitis et al. [20] examined the effect of tightening threaded components on the natural frequencies of a structure. Duffey et al. [21] presented two types of pulse-loaded vessel closures to determine the influence of bolt preload on the peal response of a closure and bolting system. Duffey [22] developed an analytical model for a bolt system subjected to single-pulse impact loads. Esteban et al. [23] presented an analytical approach to determine the energy dissipation through joints at high frequency. It was found that a significant amount of energy was dissipated after the joint. They compared the energy dissipation analytically and experimentally for both tight and loose bolts at higher frequencies. The effects of tightening threaded components on transmitted loads are not well understood.

This research has the following objectives:

1. Create an experimental setup that can be used to study impact loads transmitted to electronic components within a projectile.

2. Determine the effects of using polyurethane rubber on mitigating accelerations. 
3. Develop an approach, using the finite element method, to create models that can produce results that closely match the experimental data.

The remainder of this article is divided as follows. Section 2 contains description of the experimental setup. Section 3 explains the finite element model that is developed to simulate the experiment. Initial results are discussed in Section 4. An approach to mitigate accelerations from reaching an electronic board is presented in Section 5. Section 6 shows how the material characteristics for modeling the polyurethane rubber are obtained. Section 7 discusses the finite element model of the test fixture after including the rubber padding. Based on the results of this research a discussion of force transmissibility is included in Section 8. Section 9 includes conclusions and recommendations for future work.

\section{EXPERIMENTAL SETUP}

Figure 1 shows a typical projectile whose components are threaded or bolted together. An experimental test fixture with the same outer diameter as the original projectile is used in this research, as shown in Fig. 2. Table 1 lists the characteristics of the projectile and the test fixture.

The fixture has two main components: the nacelle and the body. The nacelle has a tapered end where an impact hammer is used, as shown in Fig. 2. As Figs 2 and 3 illustrate, the electronic board is placed between the body and the nacelle. A cylindrical board holder is used to hold the board in place. Acceleration is measured at the center of the board and the top of the body by using accelerometers, as shown in Fig. 3. Figure 4 shows the accelerometer attached to center of the board.

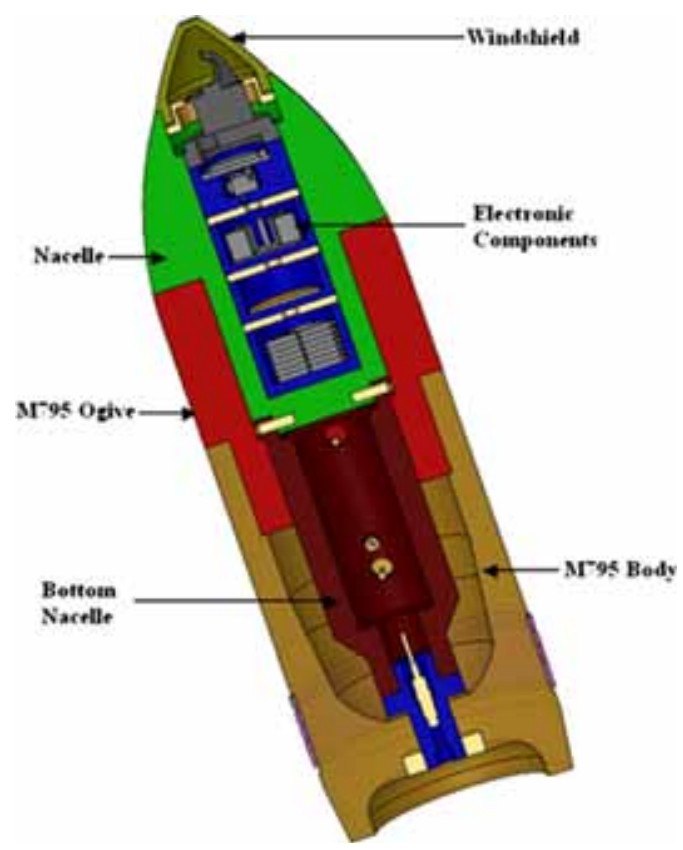

Figure 1: Section view of the original projectile. 


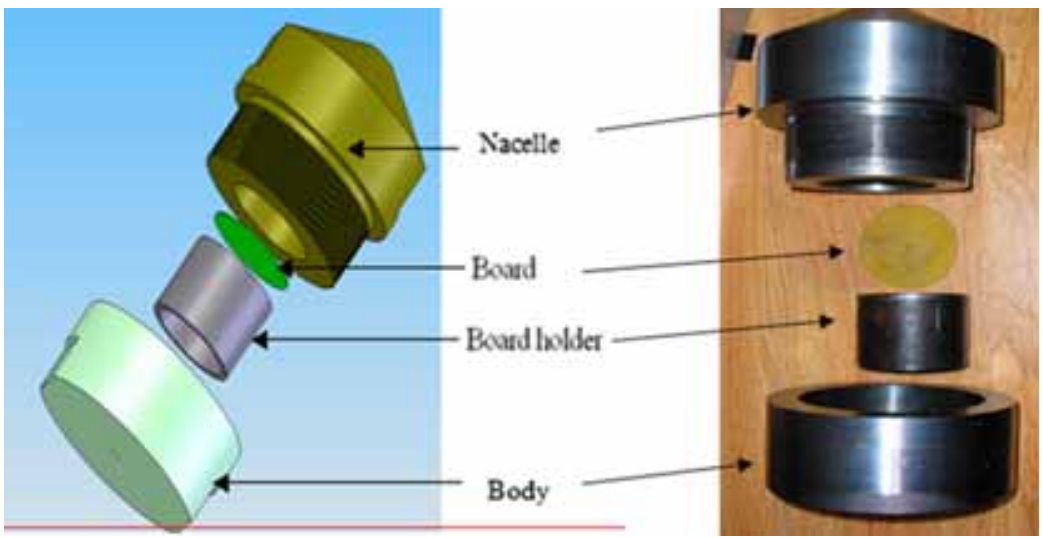

Figure 2: Illustration (left) and photo (right) of the test fixture.

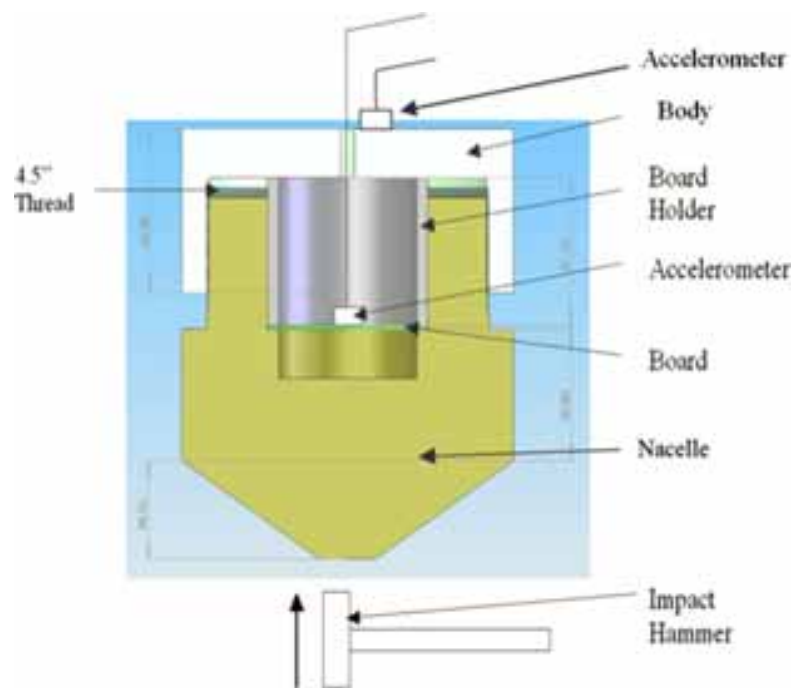

Figure 3: Sectional view of the test fixture.

Table 1: Overall characteristics of the projectile and test fixture.

Characteristic

Outer diameter of the projectile $(\mathrm{m})$

Height of the projectile (m)

Diameter of the board (m)

Mass $(\mathrm{kg})$

Center of mass along axial direction $(\mathrm{m})$

Mass moment of inertia in axial direction $\left(\mathrm{kg} \mathrm{m}^{2}\right)$
Projectile Test fixture

$\begin{array}{cc}0.1549 & 0.1540 \\ 0.4084 & 0.1689 \\ 0.0889 & 0.0737 \\ 42.06 & 17.28 \\ 0.1281 & 0.0912 \\ 0.1443 & 0.0591\end{array}$




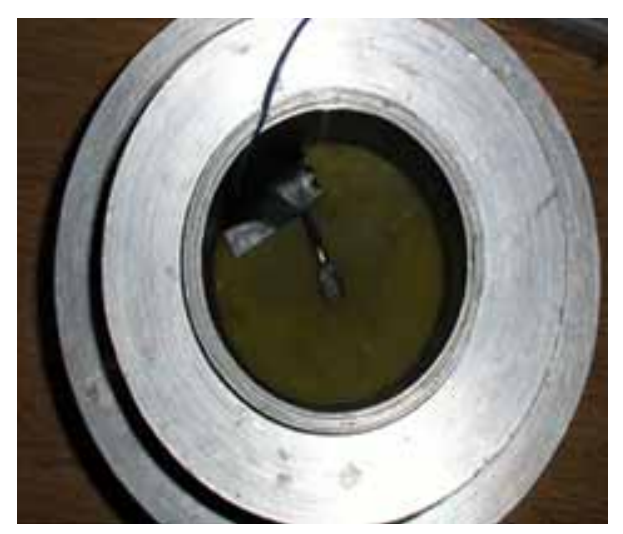

Figure 4: Accelerometer attached to the center of the board.

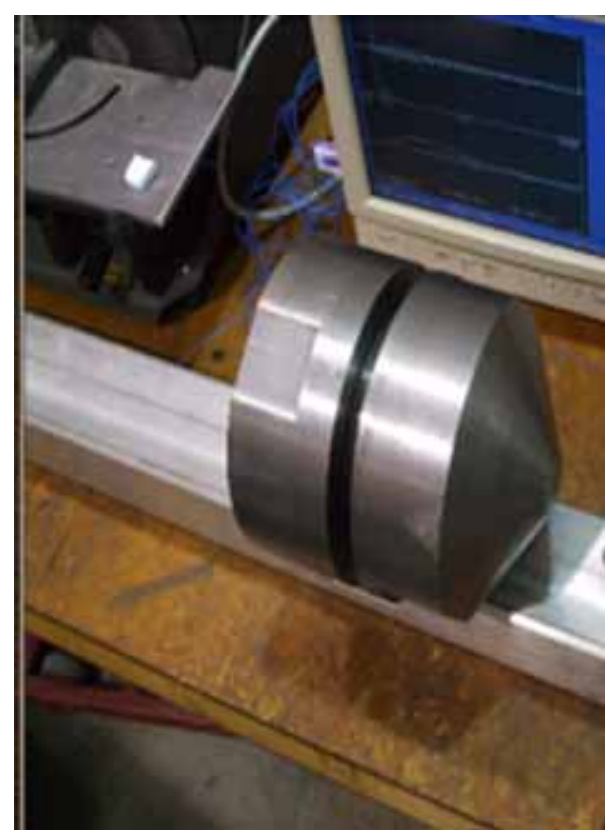

Figure 5: Layout of the fixture during test.

All components of the test fixture, other than the board, are made of 4030 structural steel. A 25-mm two-layer standard FR-4 board was used in these experiments [24]. The body and the nacelle both have 4.5 "- 15 threads. The outer surfaces of the body and the nacelle have flat surfaces to allow tightening the two components together.

As shown in Fig. 5, the fixture is laid sideways on an aluminum section during testing. Originally, the fixture was attached to a rigid frame using a wire rope. However, this method resulted in exciting additional frequencies. This setup ensures that axial accelerations dominated the acceleration signal. 
The force is applied using a modally-tuned impact hammer, PCB Model 086D05. The acceleration is measured by a PCB accelerometer, Model 352C22, which is attached using wax adhesive to the board and top of the body. The acceleration signal is processed using a PCB Piezotronics signal conditioner, Model 482A21. The acceleration signal is then recorded on a digital oscilloscope, and the acceleration is filtered using a low-pass Butterworth filter at $10,000 \mathrm{~Hz}$. This value is chosen since the accelerometer has a frequency range of 1 to $10,000 \mathrm{~Hz}$. The layout of the experimental setup is shown in Fig. 6. Figure 7 shows

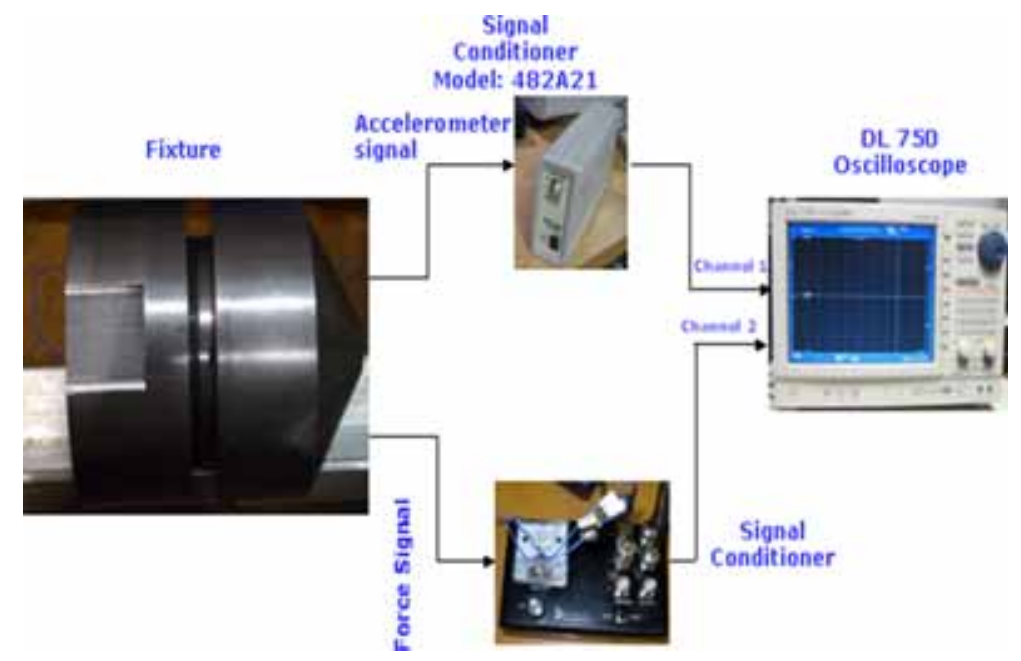

Figure 6: Experimental setup.

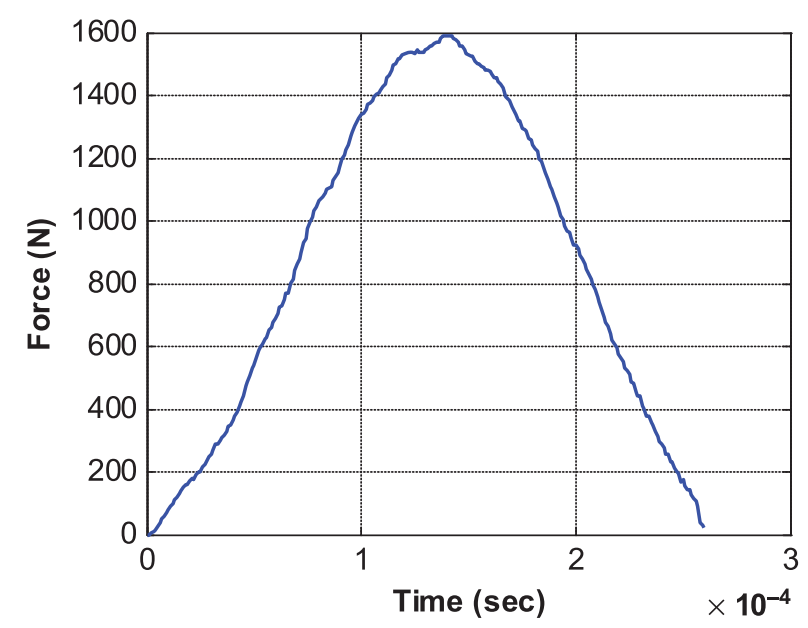

Figure 7: Force signal in the time domain. 


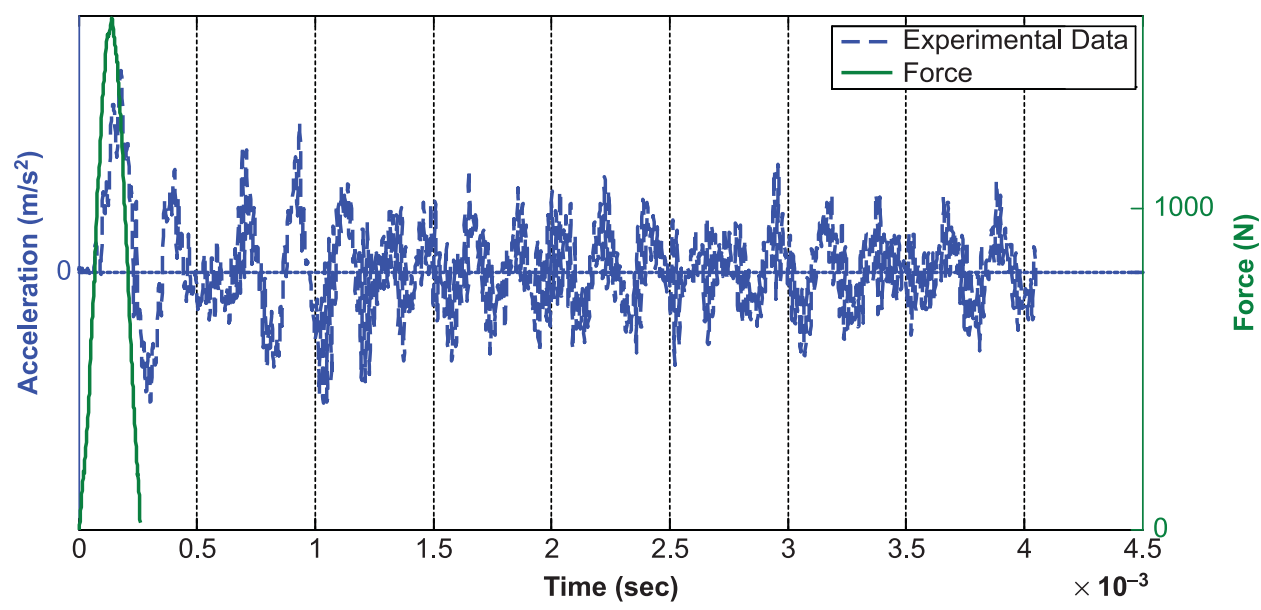

Figure 8: Typical unfiltered force-acceleration data.

a typical force profile in the time domain from an experiment. Typically, the duration of the force signal is close to $0.25 \mathrm{~ms}$, while resulting accelerations are measured for $4 \mathrm{~ms}$, as shown in Fig. 8.

\section{FINITE ELEMENT MODEL}

It was decided to use a quarter model with properly assigned boundary conditions. The test fixture is divided into smaller components. To improve the accuracy of the analysis, accelerometer is included in the model. Each of these components is meshed individually to ensure a smooth mesh transition, using 8-node brick elements. The meshed test fixture is shown in Fig. 9. The model has 47379 nodes and 42845 elements.

The board holder, nacelle, and body were made of 4030 steel, whose material properties are given in Table 2. An artificial density of the accelerometer is calculated by measuring the mass and volume. An artificially high modulus of elasticity value is used to simulate the fact that the accelerometer has a higher stiffness than the remainder of the fixture. All the steel parts and the accelerometer are modeled as MAT_ELASTIC. The material model of the electronic board is based on the experimental work of Sridharala et al. [25]; this group who studied the effects of the strain rates on the modulus of elasticity of the electronic boards by using four-point bending experiments to measure the material properties under different strain rates. The electronic board is modeled as a linear orthotropic material (MAT_ORTHOTROPIC_ELASTIC). Table 3 lists the material properties of the board.

The projectile is constrained to move only in the direction of the applied force. The LS-DYNA card used to define constraints is *BOUNDARY_SPC_NODE. All the nodes between board, board holder and nacelle are merged. The force of the hammer is uniformly applied to four nodes in a direction normal to the surface of the bottom part of the projectile, as shown in Fig. 10. These nodes corresponded to the area of force hammer. The node results at point A and B are sampled at $500 \mathrm{kHz}$ using DATABASE_NODOUT card. These nodes corresponded to the area of force hammer. LS-DYNA [26] is used to simulate the experiment. The simulation is run for $4 \mathrm{~ms}$ and computational time is 13 hours in a $3 \mathrm{GHz}$ Athlon AMD dual core, 3 GB RAM system. 


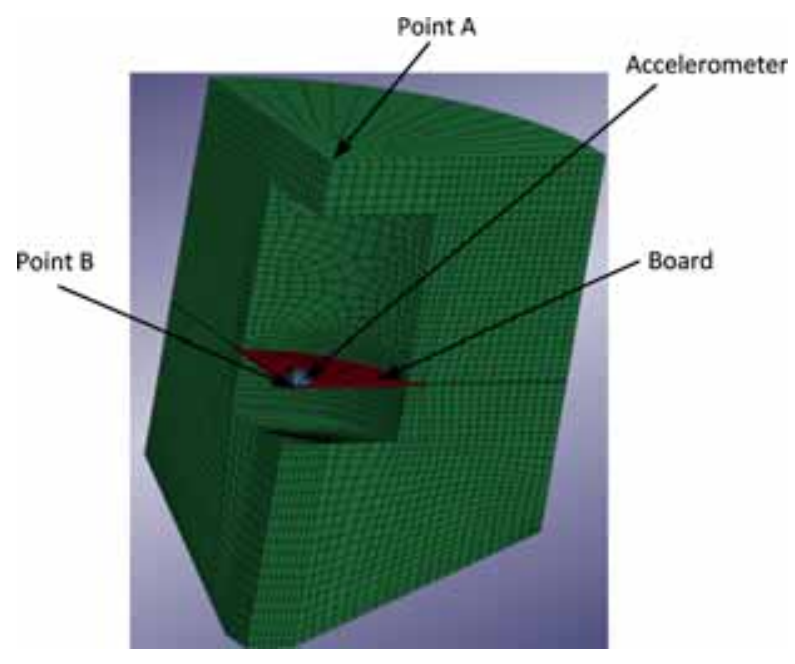

Figure 9: Meshed projectile model.

Table 2: Material properties of the fixture's metallic components.

\begin{tabular}{lcccc}
\hline Part name & Material & Young's modulus $\left(\mathrm{kg} / \mathrm{m}^{2}\right)$ & Density $\left(\mathrm{kg} / \mathrm{m}^{3}\right)$ & Poisson ratio \\
\hline $\begin{array}{l}\text { Board holder, } \\
\text { nacelle, body }\end{array}$ & 4030 Steel & $1.9 \mathrm{E}+11$ & 7833.4 & 0.27 \\
\begin{tabular}{l} 
Accelerometer \\
\hline
\end{tabular} & - & $2.1 \mathrm{E}+12$ & 2178.4 & 0.27 \\
\hline
\end{tabular}

Table 3: Material properties of the electronic board.

\begin{tabular}{lccc}
\hline Density $\left(\mathrm{kg} / \mathrm{m}^{3}\right)$ & Poisson ratio & Young's modulus $\left(\mathrm{N} / \mathrm{m}^{2}\right)$ & Modulus of rigidity $\left(\mathrm{N} / \mathrm{m}^{2}\right)$ \\
\hline 1602.6 & $\gamma_{x y}=0.18$ & $\mathrm{E}_{\mathrm{x}}=2.3 \mathrm{E}+10$ & $\mathrm{G}_{\mathrm{xy}}=2.9 \mathrm{E}+09$ \\
& $\gamma_{y z}=0.18$ & $\mathrm{E}_{\mathrm{y}}=9.1 \mathrm{E}+9$ & $\mathrm{G}_{\mathrm{yz}}=2.9 \mathrm{E}+09$ \\
& $\gamma_{x z}=0.14$ & $\mathrm{E}_{\mathrm{z}}=2.3 \mathrm{E}+10$ & $\mathrm{G}_{\mathrm{xz}}=3.7 \mathrm{E}+09$ \\
\hline
\end{tabular}

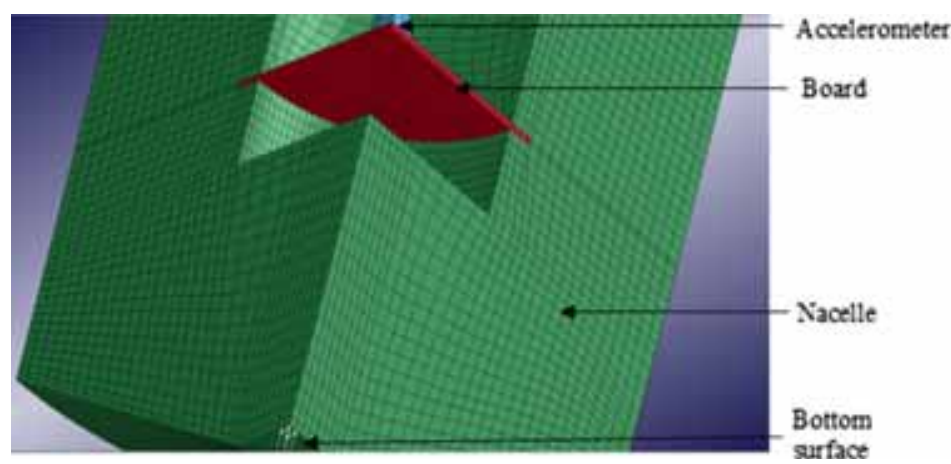

Figure 10: Direction of force. 


\section{INITIAL RESULTS}

The experiment started by considering the effects of pre-tightening torque on the transmitted impact. When the two threaded components are tightened, a tightening force, $F_{i}$, is induced in these two parts. The corresponding tightening torque, $T_{i}$, could be calculated according to the following formula, Juvinal et al. [27]:

$$
T_{i}=\frac{F_{i} d_{p}}{2}\left(\frac{\mu \pi d_{p}+L}{\pi d_{p}-L}\right)
$$

where, $A_{t}$ is the tensile stress area,

$d_{p}$ is the pitch diameter,

$F_{i}$ is the coefficient of friction, and

$L$ is the lead.

Figure 11 illustrates the effects of tightening the preload force of the test fixture on the frequency and acceleration of Point $A$ at the center of the top surface of the housing and of Point B at the center of the top surface of the board. The results show that the frequencies measured on the body significantly increases as the tightening torque increases. On the other hand, frequencies measured on the board experience a more limited change, and are fairly stable. Conversely, accelerations on the board significantly decrease as the tightening torque increases, as shown in Fig. 12. It is observed that accelerations measured on the body did not change with tightening torque. Therefore, it can be concluded that applying a tightening torque of about $170 \mathrm{Nm}$ ensures acceptable behavior in the experimental fixture.

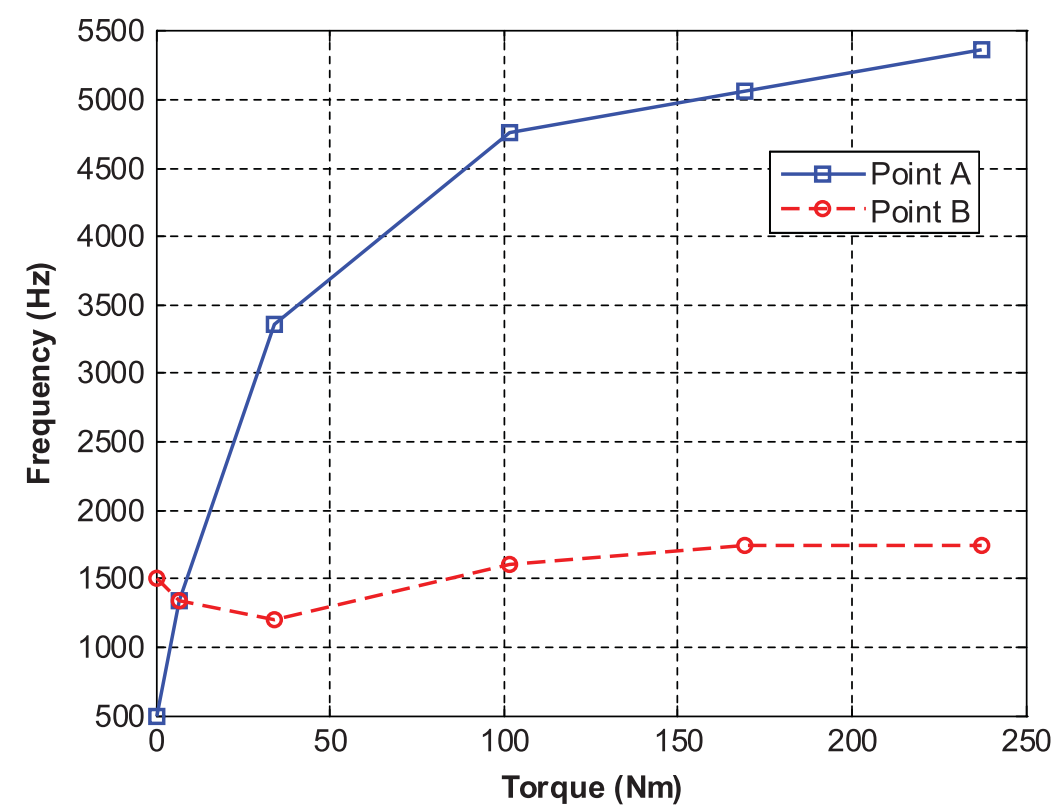

Figure 11: Comparison of frequencies on the board and housing for various torque levels. 


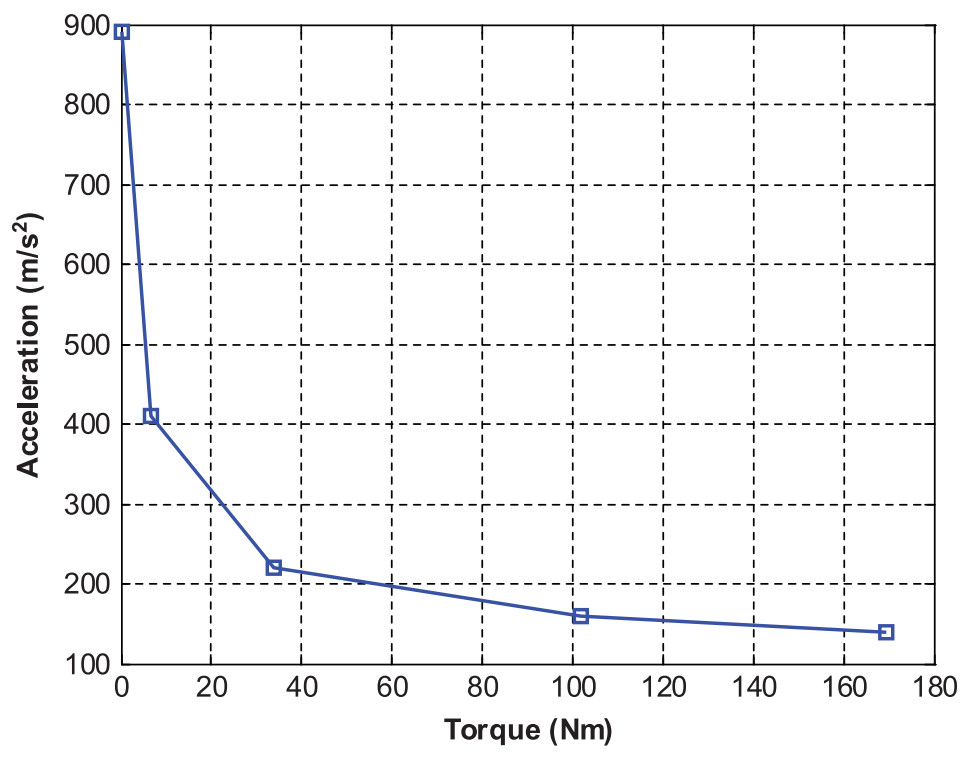

Figure 12: Peak acceleration on the board with tightening torque.

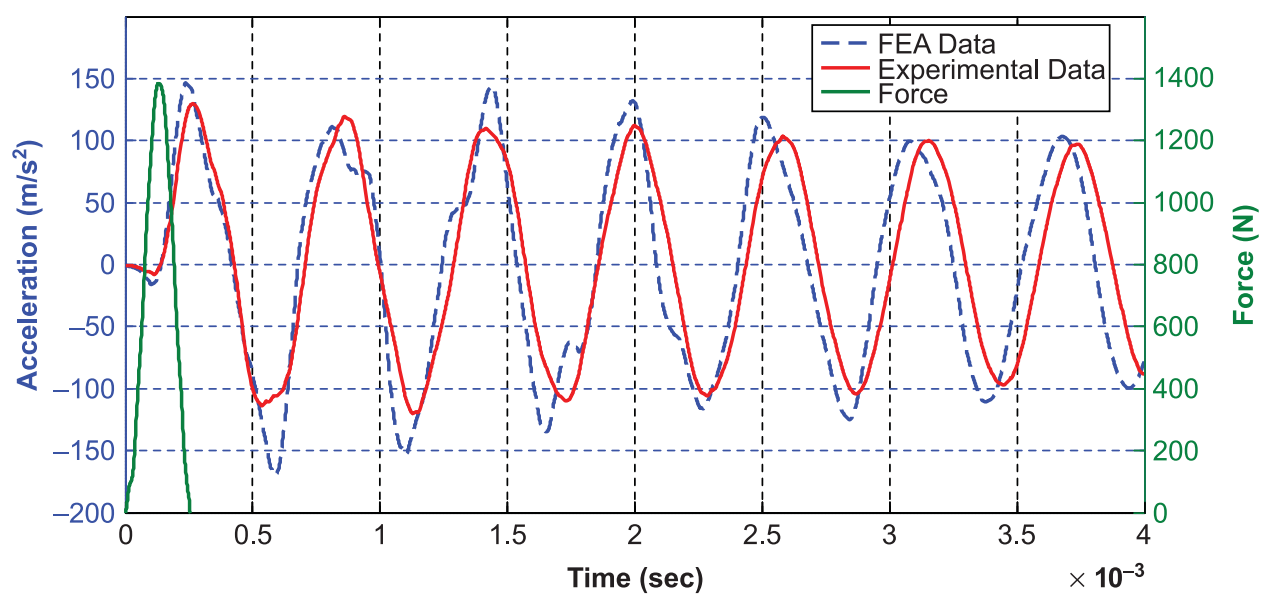

Figure 13: Comparison of experimental and FEA simulation results at the lower force level.

Figure 13 presents the comparison between FEA and experiment accelerations on the board at $170 \mathrm{Nm}$ torque due to the lower force, in the order of 1,400 N. The Figure shows that the FEA results closely match the experimental data. The experiment is repeated using higher force levels, in the order of 12,000 N, as illustrated in Fig. 14. In both cases, the FEA model is able to capture the main acceleration wave; however, some of the higher order frequencies 


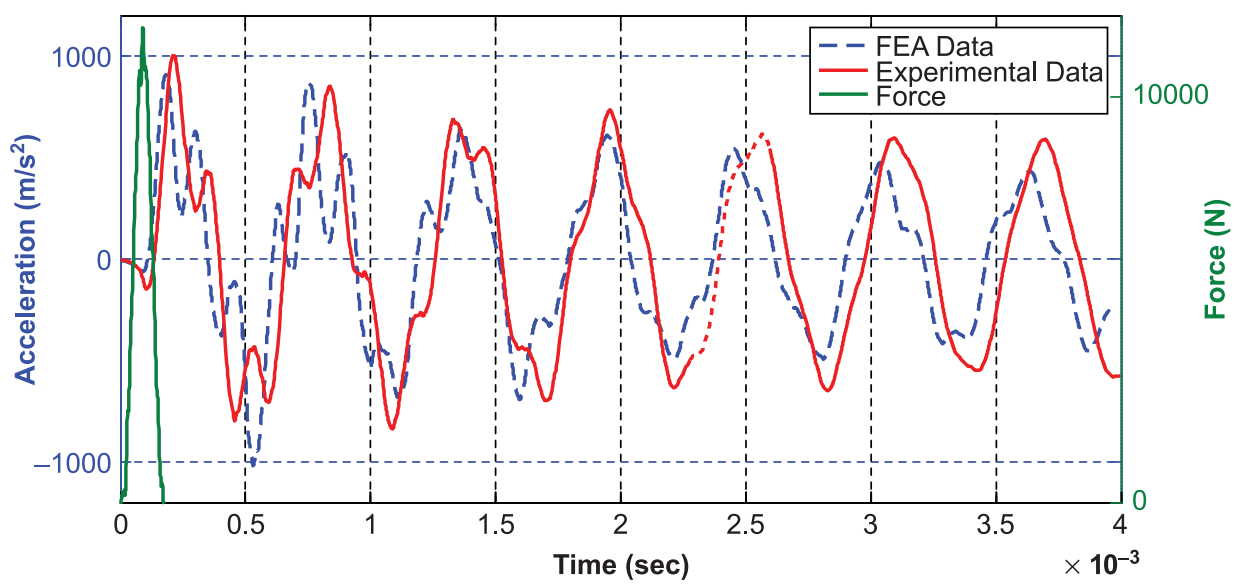

Figure 14: Comparison of experimental and FEA simulation results at the higher force level.

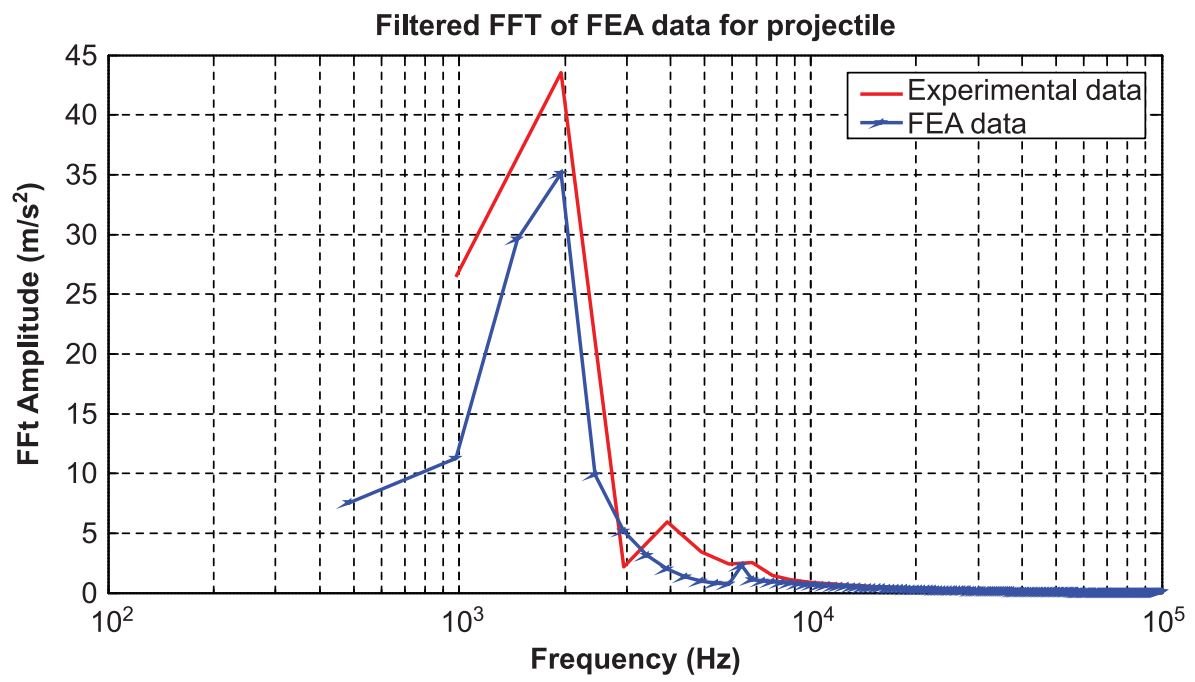

Figure 15: FFT of filtered experimental and FEA data at the lower force level.

are missing, which is confirmed by studying the fast Fourier transform (FFT) analyses in Figs 15 and 16. These Figures show that the frequency at $2000 \mathrm{~Hz}$ closely matched; however, the FEA missed the second natural frequency, $4000 \mathrm{~Hz}$. The third frequency was shifted by $488 \mathrm{~Hz}$ when compared to the experimental data. Increasing the mesh density in the axial direction of the board produced similar results. 


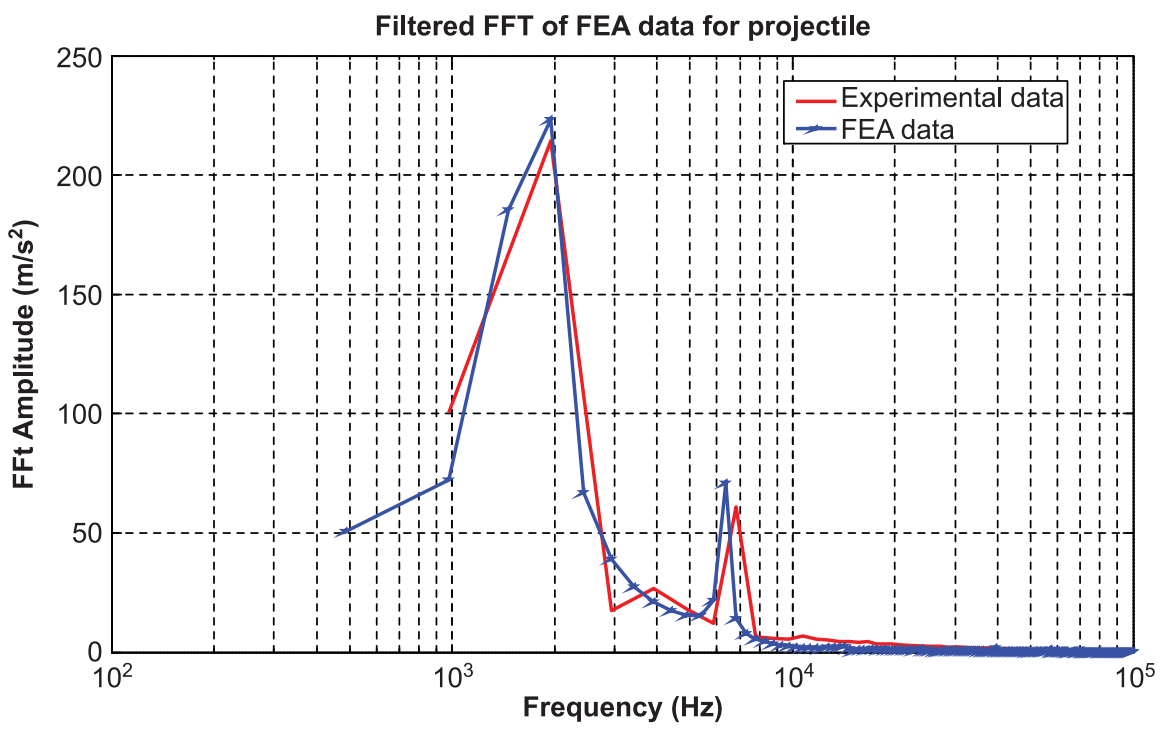

Figure 16: FFT of filtered experimental and FEA data at the higher force level.

\section{ACCELERATION MITIGATION}

This section describes an experiment to mitigate accelerations on the board by using polyurethane rubber [28], whose properties are listed in Table 4. It was decided to support the board by using rubber paddings having $1.5-\mathrm{mm}$ and $3-\mathrm{mm}$ thicknesses. The rubber paddings are placed above the board and held in position by the board holder, as shown in Fig. 17. The rubber paddings are cut to form a ring with inner and outer diameters measuring $63.6 \mathrm{~mm}$ and $73.7 \mathrm{~mm}$, respectively; these match the dimensions of the board holder.

Results of the experiments for the 1.5-mm-thick rubber are shown in Figs 18 and 19 for various force levels. Similarly, results for 3-mm-thick rubber are shown in Figs 20 and 21 for various force levels. The results indicated that using 1.5-mm- and 3-mm-thick rubber dampened the accelerations.

The results of these experiments are assessed by calculating the damping ratio for each case by using the Half-Power Bandwidth method [29]. This method, which is used in the frequency domain, is based on the observation that the shape of the frequency response is

Table 4: Polyurethane rubber properties.

\begin{tabular}{ll}
\hline Durometer & Medium soft \\
\hline Durometer rating & $40 \mathrm{~A}$ \\
Density & $1185.3 \mathrm{~kg} / \mathrm{m}^{3}$ \\
Tensile strength & $5 \mathrm{MPa}$ \\
Stretch limit & $490 \%$ \\
\hline
\end{tabular}




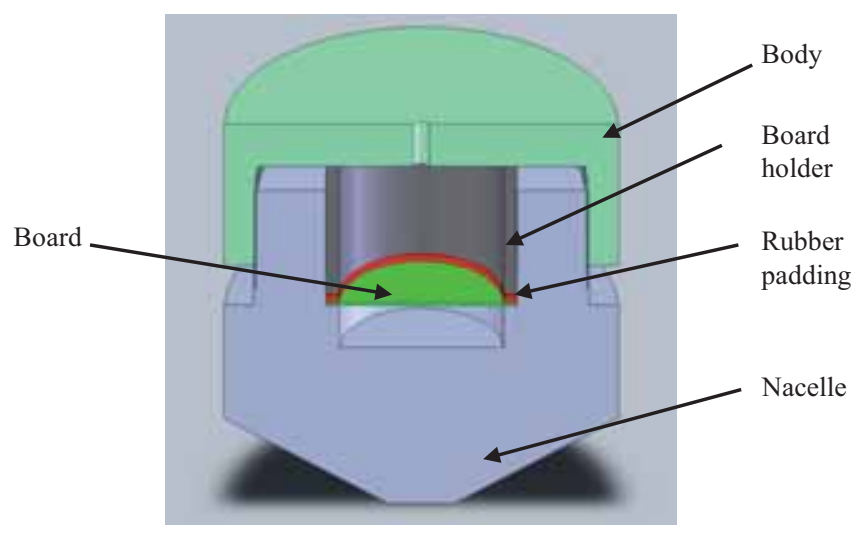

Figure17: Sectional view of the test fixture with rubber padding.

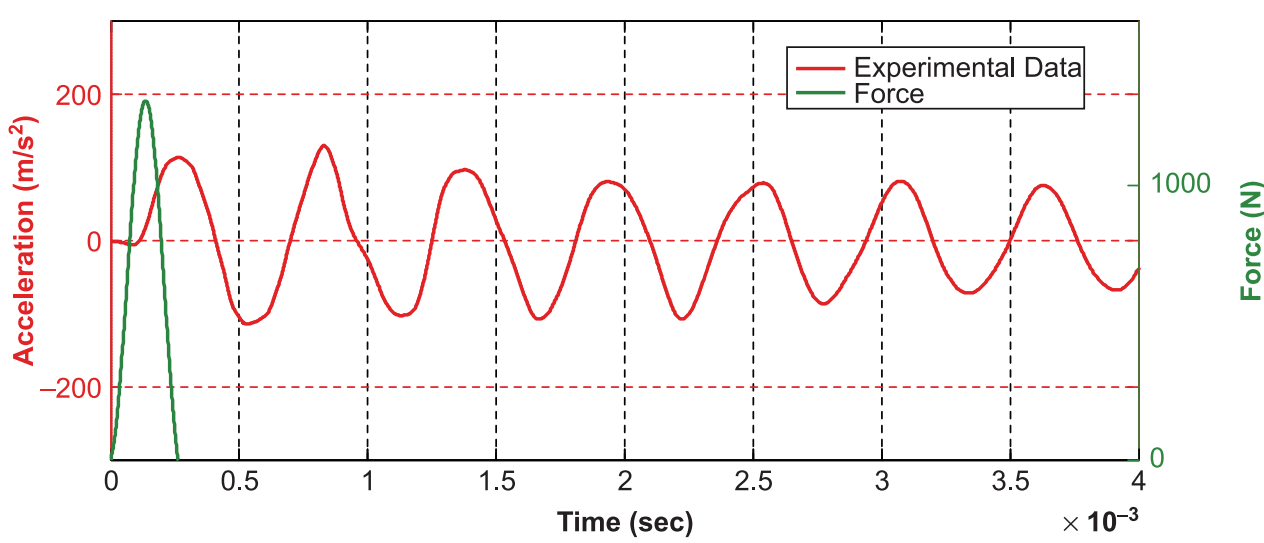

Figure 18: Experimental results with 1.5-mm-thick rubber (low force case).

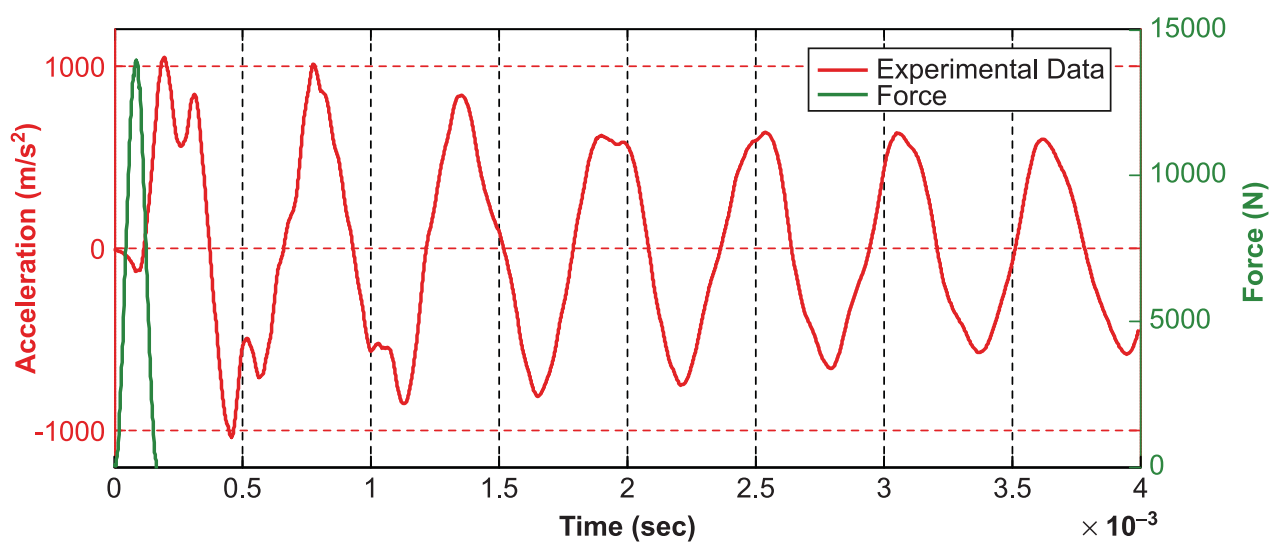

Figure 19: Experimental results with 1.5-mm-thick rubber (high force case). 


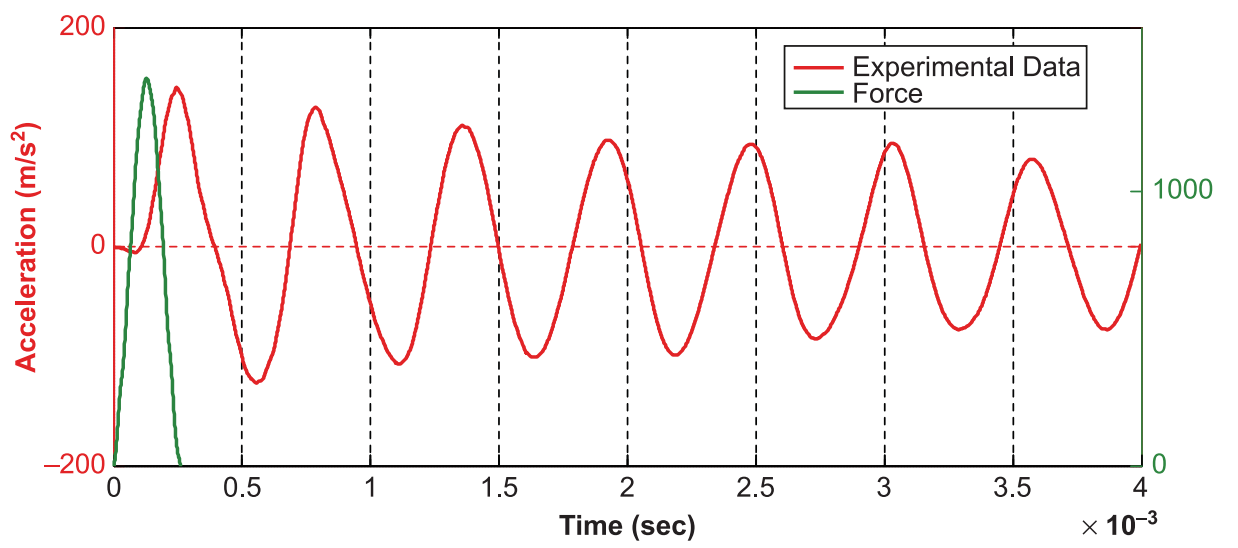

$\bar{z}$
$\vdots$
인

Figure 20: Experimental result with 3-mm-thick rubber (low force case).

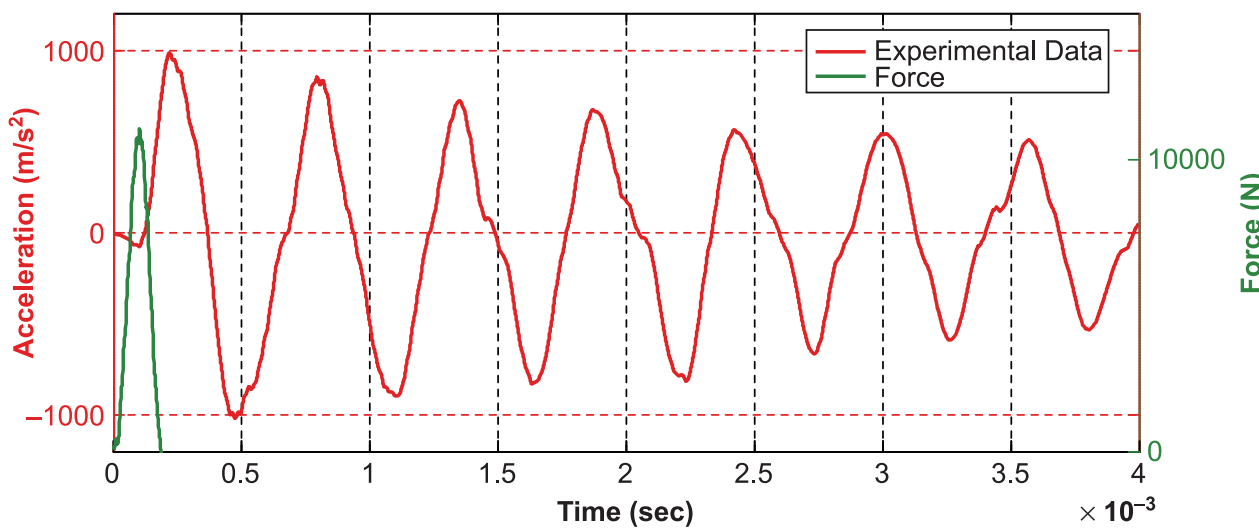

Figure 21: Experimental result with 3-mm-thick rubber (high force case).

controlled by the amount of damping in the system. Therefore, it is possible to estimate the damping ratio from the properties of the frequency curve. The damping ratio is calculated by identifying the two frequencies that are adjacent to the first natural frequency of the system, $R_{d}$, and whose magnitudes are equal to $\frac{R_{d}}{\sqrt{2}}$, as shown in Fig. 22. The damping ratio is calculated according to the following equation:

$$
\xi=\frac{f_{2}-f_{1}}{f_{2}+f_{1}}
$$

A typical frequency response of experiments with the lower force level is shown in Fig. 23. This Figure shows a frequency shift in the case of the 3-mm-thick rubber. It also shows that when rubber is added, the slope of the curve changes significantly. Table 5 lists the average 


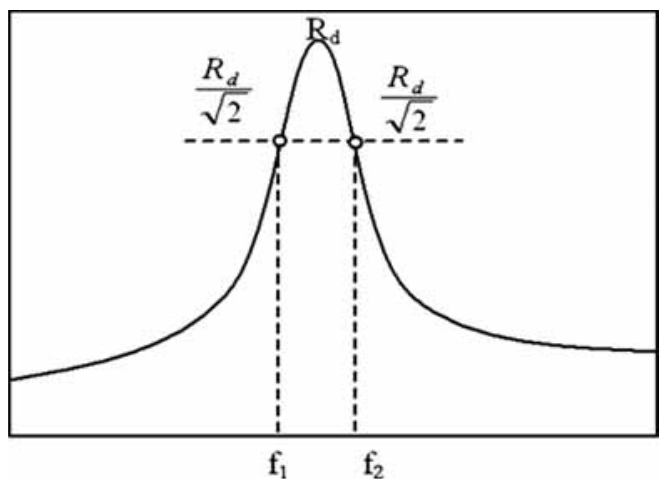

Figure 22: Half-power method to estimate damping.

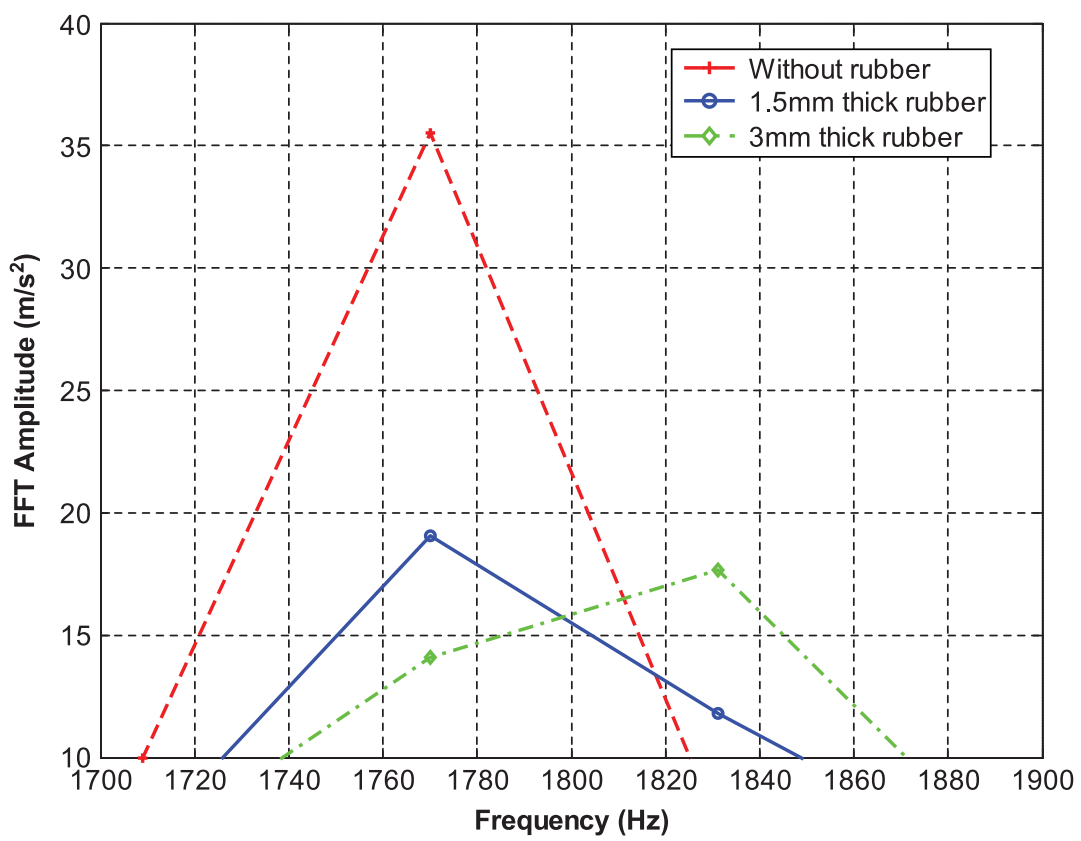

Figure 23: Typical frequency response at lower force levels.

values for the damping ratio and the corresponding standard deviation for the experiments conducted at lower force levels (six experiments in each case). The same procedure is repeated at higher force levels. The results are shown in Table 6.

The results of Tables 5 and 6 indicate that the damping ratio on the electronic board increases by using rubber packing. In addition, they indicate that the damping ratio is fairly constant for a given rubber thickness with the range of forces considered in this study. 
Table 5: Damping ratio - lower force level.

\begin{tabular}{lccc}
\hline Case & $\begin{array}{l}\text { Number of } \\
\text { experiments }\end{array}$ & $\begin{array}{l}\text { Average } \\
\text { damping ratio }\end{array}$ & $\begin{array}{l}\text { Standard } \\
\text { deviation }\end{array}$ \\
\hline Without rubber & 5 & 0.0133 & $4.89 * 10^{-5}$ \\
1.5-mm-thick rubber & 5 & 0.0210 & $8.16^{*} 10^{-5}$ \\
3-mm-thick rubber & 5 & 0.0278 & $4.06 * 10^{-4}$ \\
\hline
\end{tabular}

Table 6: Damping ratio - higher force level.

\begin{tabular}{lccc}
\hline Case & $\begin{array}{l}\text { Number of } \\
\text { experiments }\end{array}$ & $\begin{array}{l}\text { Average } \\
\text { damping ratio }\end{array}$ & $\begin{array}{l}\text { Standard } \\
\text { deviation }\end{array}$ \\
\hline Without rubber & 5 & 0.0152 & $7.45^{*} 10^{-6}$ \\
1.5-mm-thick rubber & 5 & 0.0199 & $7.54 * 10^{-4}$ \\
3-mm-thick rubber & 5 & 0.0281 & $1.47 * 10^{-3}$ \\
\hline
\end{tabular}

\section{EXPERIMNETRAL IDENTIFICATION OF MATERIAL CHARACTERISTICS OF POLYURETHANE RUBBER}

This section describes the experimental method for finding the properties of rubber that can be used in FEA. Polyurethane rubber is composed of a base rubber, fillers, and a curing agent. Additional components may include antioxidants, adhesion agents, flame retardant agents, and special process-enhancing chemical additives. Every ingredient of a rubber may affect the physical properties, either independently or dependently of each other. Similarly, the mixing and curing processes are also critical in determining these properties. Therefore, it is necessary to experimentally identify material characteristics of the particular rubber used in this research as these values may not be readily available.

Compression tests on the rubber were conducted using the United Test Systems universal testing machine. A 12.7-mm-diameter specimen is used for the compression test, as shown in the Fig. 24. A true stress-true strain curve is shown in Fig. 25. As expected, rubber experiences different phases during the test. Results showed that Young's modulus of elasticity at the force induced by the tightening torque was 1.70 MPa for 3-mm-thick rubber and 2.60 MPa for 1.5-mm-thick rubber. The amount of the extension in the padding when compressed in the projectile is found from the reduction in thickness and force acting on the rubber, assuming the volume remains constant for the rubber. Experimental results showed that the material behaved linearly in the neighborhood of these values.

\section{FEA OF THE TEST FIXTURE WITH RUBBER PADDING}

This section describes modeling of polyurethane rubber. The process of developing the model is explained in Section 3. The model with 1.5-mm-thick rubber layer has 58,959 nodes and 53,314 elements while the model with 3-mm-thick model has 65221 nodes and 59415 elements. Polyurethane rubber is modeled as MAT_ELASTIC material model with Young's modulus of elasticity derived from previous section. A Poisson ratio of 0.49 is used for both 


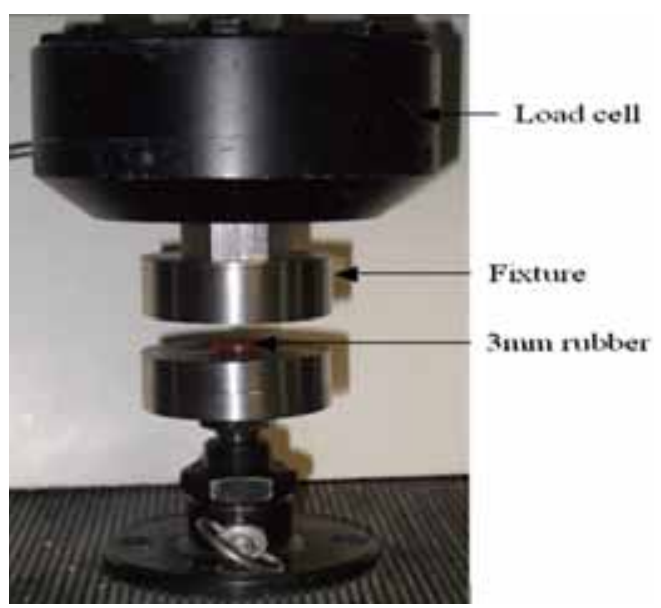

Figure 24: Fixture for compression test.

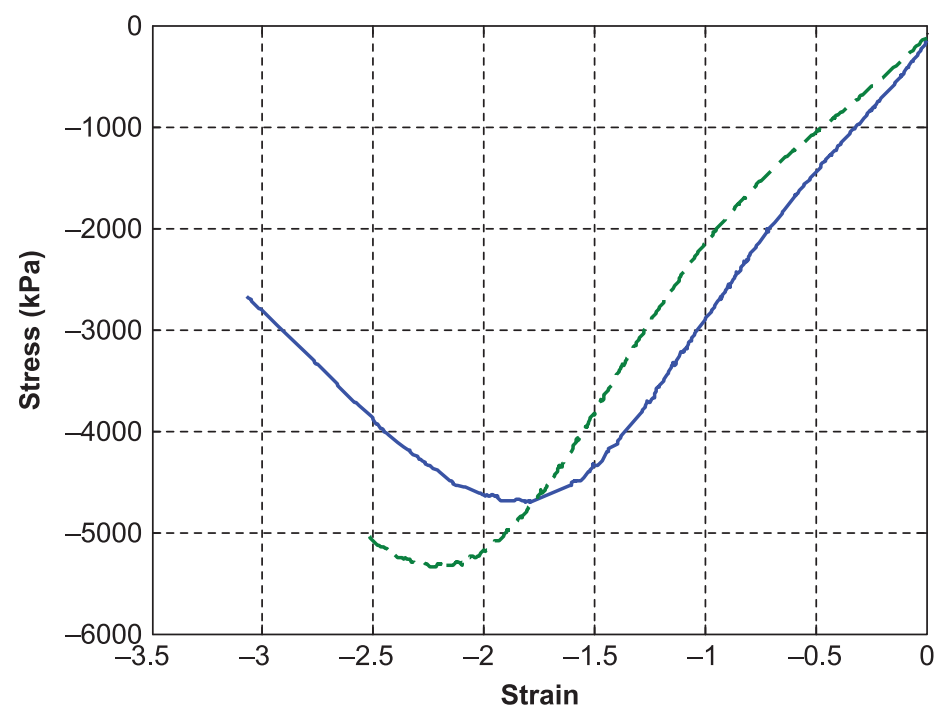

Figure 25: True stress-true strain curve for the 1.5-mm- and 3-mm-thick polyurethane rubber specimens.

1.5-mm- and 3-mm-thick rubber. Since polyurethane rubber is a visco-elastic material, accounting for its damping is important for accurate modeling. The damping effect is represented in the FEA model by means of Rayleigh damping as a linear combination of alpha and beta damping parameters:

$$
[C]=\alpha[M]+\beta[K]
$$


where, $\alpha$ and $\beta$ are the damping coefficients. $C, M$, and $K$ are the damping, mass, and stiffness matrices, respectively. The first term in the above equation dampens out the low frequencies of the system; the second term dampens the higher order frequencies. The damping coefficients can be calculated using the following equation:

$$
\xi=\frac{a}{2 \omega_{1}}+\frac{\beta \omega_{1}}{2}=\frac{a}{2 \omega_{2}}+\frac{\beta \omega_{2}}{2}
$$

Based on the experimental results, a frequency range of $1700 \mathrm{~Hz}$ to $1900 \mathrm{~Hz}$ is selected. The values of $\alpha$ and $\beta$ are listed in Table 7 for the 1.5-mm- and 3-mm-thick polyurethane rubber layers. The damping coefficients $\alpha$ and $\beta$ are included in the finite element code using DAMPING_GLOBAL and DAMPING_PART_STIFFNESS cards respectively.

The finite element model is similar to the one introduced earlier, except for including the rubber padding, as shown in Fig. 26. The padding was extended to indicate its shape under the tightening load. The amount of extension in the padding was calculated from the compression test, as explained in the previous section. Nodes between the extended surface of rubber and the board are merged.

Figures 27 through 30 compare the experimental results with FEA and FFT plots for 1.5-mm- and 3-mm-thick rubber paddings at lower and higher force level respectively. The results clearly show that these paddings reduced the higher order frequencies.

Table 7: Rayleigh damping coefficients.

\begin{tabular}{llc}
\hline & Alpha $(\alpha)$ & Beta $(\beta)$ \\
\hline 1.5-mm-thick rubber & 225.38 & $0.1769 * 10^{-5}$ \\
3-mm-thick rubber & 311.9 & $0.2511 * 10^{-5}$ \\
\hline
\end{tabular}

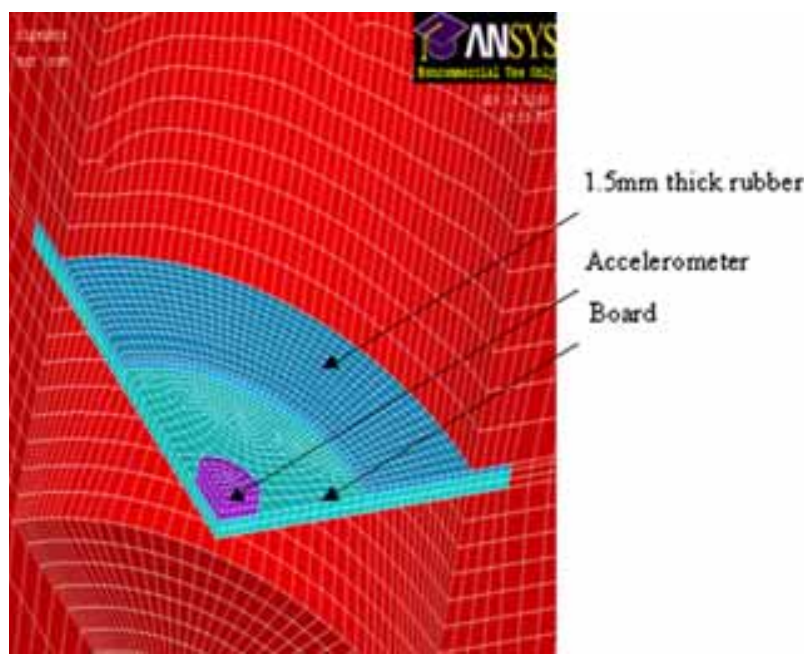

Figure 26: Meshed projectile model with rubber. 


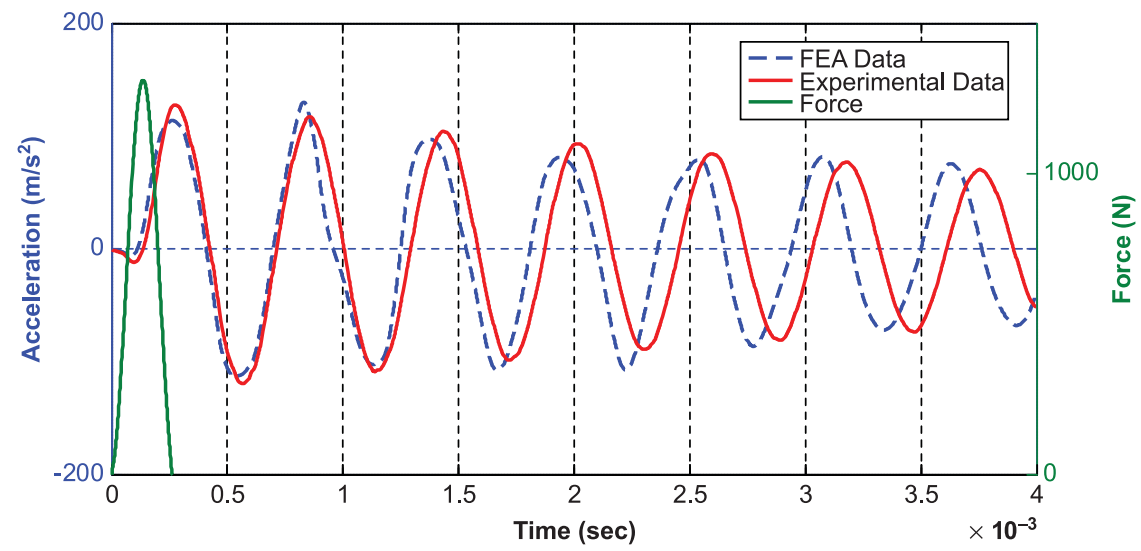

Figure 27: Comparison of FEA simulations with experiments for the 1.5-mm-thick rubber (lower force case).

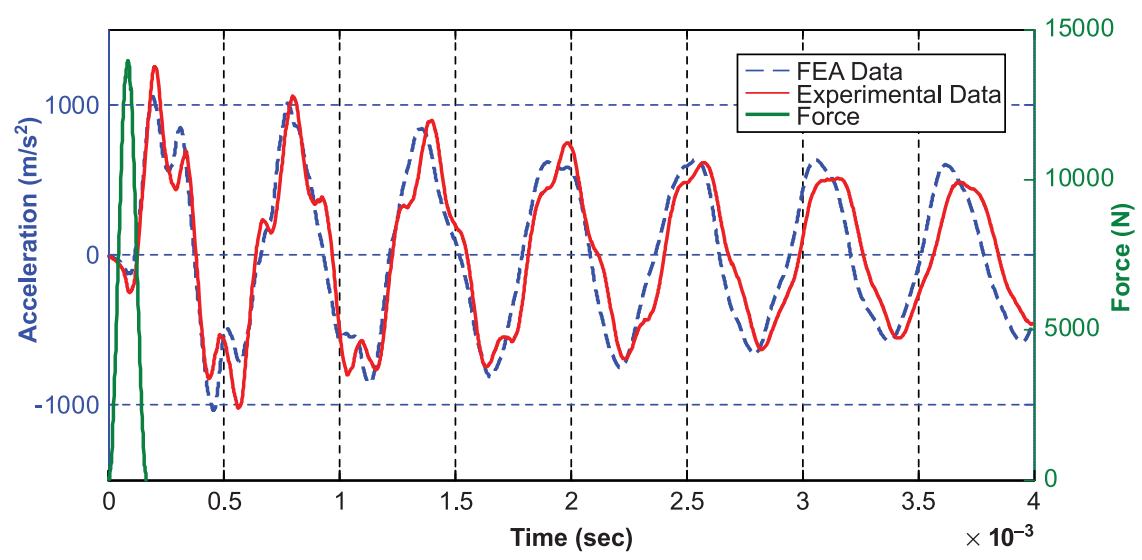

Figure 28: Comparison of FEA simulations with experiments for the 1.5-mm-thick rubber (higher force case).

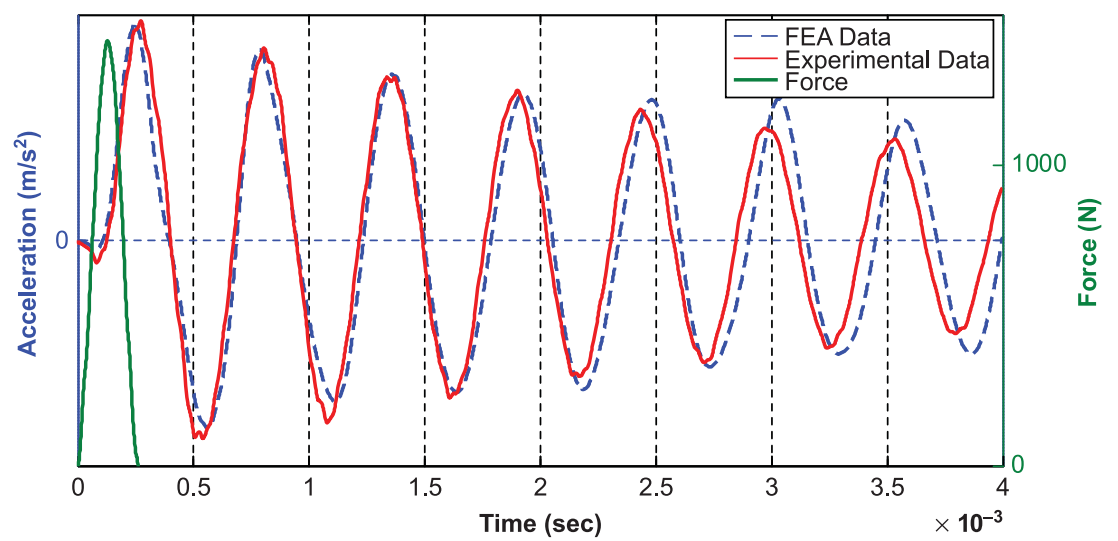

Figure 29: Comparison of FEA simulations with experiments for the 3-mm-thick rubber (lower force case). 


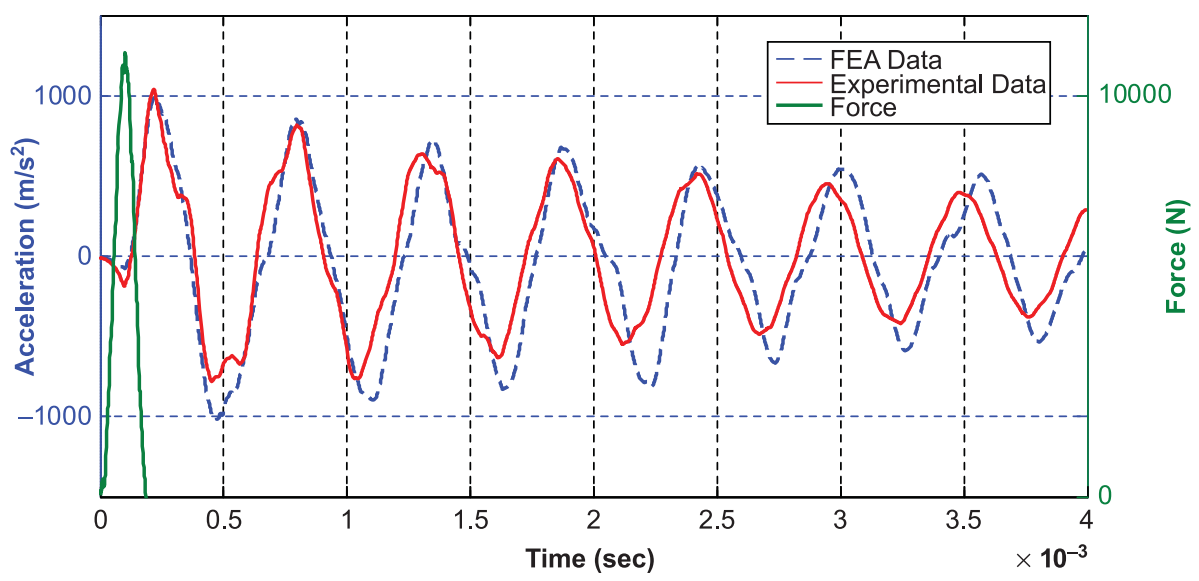

Figure 30: Comparison of FEA simulations with experiments for the 3-mm-thick rubber (higher force case).

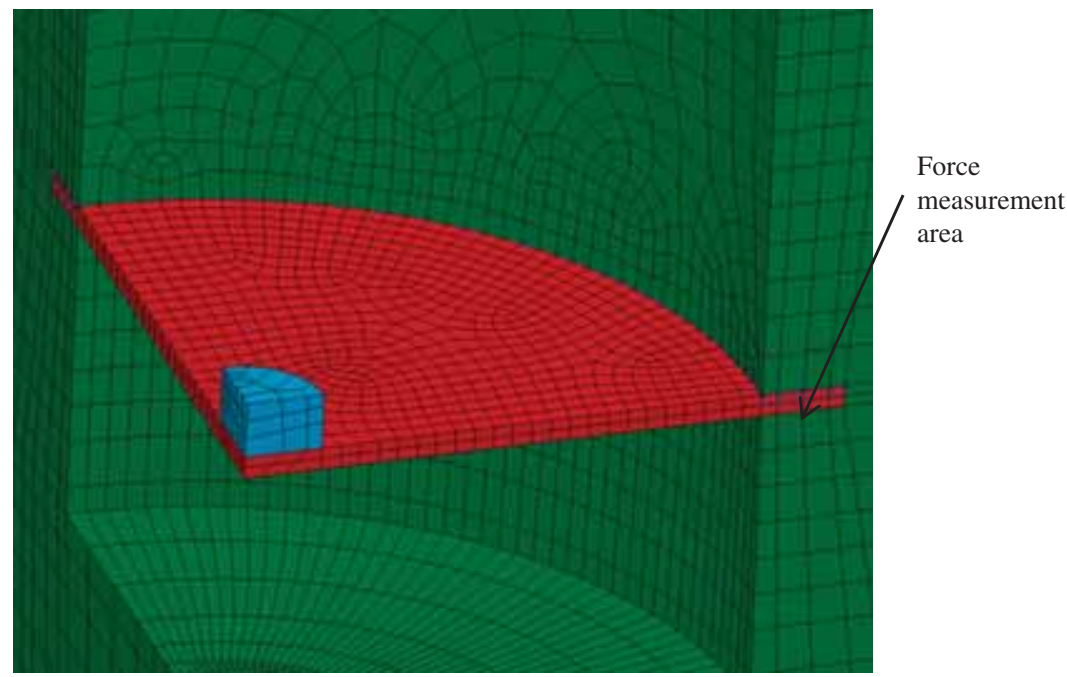

Figure 31: FEA model with force output.

\section{FORCE TRANSMISSIBILITY TO THE BOARD}

The forces transmitted to the board at the three case (without rubber, with 1.5-mm-thick rubber, and 3-mm-thick rubber) are compared. These forces are calculated using the finite element codes developed earlier in this work. The force between the board and the board holder is measured using DATABASE_CROSS_SECTION card in LS-Dyna. Figure 31 shows area used for force measurement.

Knowing the force input and force on the board, the force transmissibility can be calculated as shown in the following eqn (5). The percentage reduction in force transmissibility is 
calculated with respect to the force transmissibility without rubber. Tables 8 and 9 show the results of transmissibility and percentage reduction in the force transmissibility for lower and higher force cases. Results of these two tables show that the force transmitted to the board can be reduced more than $90 \%$ by using polyurethane rubber packing.

$$
\text { Transmissibility }=\frac{\text { Peak force on board }}{\text { Peak input force }}
$$

Table 8: Force transmissibility at lower force case.

\begin{tabular}{|c|c|c|c|c|c|c|}
\hline & $\begin{array}{l}\text { Experimental } \\
\text { input } \\
\text { force } \\
\text { time } \\
\text { duration } \\
(\mathrm{ms})\end{array}$ & $\begin{array}{l}\text { FEA } \\
\text { output } \\
\text { force } \\
\text { time } \\
\text { duration } \\
\text { (ms) }\end{array}$ & $\begin{array}{l}\text { Input } \\
\text { force } \\
(\mathrm{N})\end{array}$ & $\begin{array}{l}\text { Force } \\
\text { on } \\
\text { board } \\
(\mathrm{N})\end{array}$ & Transmissibility & $\begin{array}{l}\text { Percentage } \\
\text { reduction } \\
\text { in force } \\
\text { transmissibility }\end{array}$ \\
\hline $\begin{array}{l}\text { Without } \\
\text { Rubber }\end{array}$ & 0.25 & 0.232 & 1384.95 & 64.8 & 0.046 & $\sim$ \\
\hline $\begin{array}{l}\text { 1.5-mm- } \\
\text { Thick } \\
\text { Rubber }\end{array}$ & 0.26 & 0.236 & 1310.61 & 2.38 & $1.81 * 10^{-3}$ & 96.06 \\
\hline $\begin{array}{l}\text { 3-mm- } \\
\text { Thick } \\
\text { Rubber }\end{array}$ & 0.25 & 0.236 & 1414.36 & 4.835 & $3.40 * 10^{-3}$ & 92.50 \\
\hline
\end{tabular}

Table 9: Force transmissibility at higher force case.

\begin{tabular}{|c|c|c|c|c|c|c|}
\hline & $\begin{array}{l}\text { Experimental } \\
\text { input } \\
\text { force } \\
\text { time } \\
\text { duration } \\
(\mathrm{ms})\end{array}$ & $\begin{array}{l}\text { FEA } \\
\text { output } \\
\text { force } \\
\text { time } \\
\text { duration } \\
(\mathrm{ms})\end{array}$ & $\begin{array}{l}\text { Input } \\
\text { force } \\
(\mathrm{N})\end{array}$ & $\begin{array}{l}\text { Force } \\
\text { on } \\
\text { board } \\
(\mathrm{N})\end{array}$ & Transmissibility & $\begin{array}{l}\text { Percentage } \\
\text { reduction } \\
\text { in force } \\
\text { transmissibility }\end{array}$ \\
\hline $\begin{array}{l}\text { Without } \\
\text { Rubber }\end{array}$ & 0.172 & 0.168 & 11152 & 643.86 & 0.057 & $\sim$ \\
\hline $\begin{array}{l}1.5-\mathrm{mm}- \\
\text { Thick } \\
\text { Rubber }\end{array}$ & 0.179 & 0.132 & 11463 & 34.38 & $2.99 * 10^{-3}$ & 94.75 \\
\hline $\begin{array}{l}\text { 3-mm- } \\
\text { Thick } \\
\text { Rubber }\end{array}$ & 0.184 & 0.168 & 10923 & 41.33 & $3.78 * 10^{-3}$ & 93.36 \\
\hline
\end{tabular}




\section{CONCLUSION}

Electronic components within a projectile are subjected to severe shock loadings during and after launch. Realistic extensive experimental tests of such components can be prohibitively expensive. This paper presents an approach to mitigate the vibration to the board by using a rubber compound as a packing material. A test fixture was designed to mimic a projectile with an electronic board inside. The effect of tightening torque on the frequency and amplitude of board accelerations was investigated. Recommendations for tightening torque needed to ensure that consistent results were presented. Based on the results of these preliminary studies, experimental assessments were conducted using $1.5-\mathrm{mm}$ - and 3-mm-thick rubber packing. Using the Half-Power Bandwidth method, the damping ratio was calculated for each case. Results show that the damping ratio was proportional to the thickness of the rubber packing.

The paper also proposes an approach for finite element modeling of this problem, which can be used as a design tool in the future. Using finite element method, the force transmissibility on the board was found and result shows that the transmissibility reduced more than $90 \%$ by using rubber packing. This research showed that threaded joints could be modeled as a single structure, without modeling threads, once a certain range of tightening torque was reached. At higher force levels, higher frequencies were excited that were not identified using FEA. Further study can be done in the FEA model to match the experimental results.

\section{REFERENCES}

[1] Berman, M., Hopkins, D., Powers, B. \& Minnicino, M., Numerical and experimental modeling of the transition from transient to quasi-static loading of printed wiring assemblies. SEM Annual Conference and Exposition on Experimental and Applied Mechanics, June 2-4, 2003.

[2] Cordes, J.A., Carlucci, D. \& Jafar, R., Dynamics of a simplified 155-MM projectile, Army TACOM-ARDEC, (internal report).

[3] Heaslip, G. \& Punch, J., Analysis of experimental shock and impact response data of a printed wire board. Electronic and Photonic Packing, Electrical Systems and Photonic Design, and Nanotechnology, 3, pp. 125-133, 2003.

[4] Hopkins, D.A. \& Wilkerson, S.A., Analysis of a balanced breech system for the M1A1 main gun system using finite element techniques. Computers in Engineering, Proceedings of the International Conference and Exhibit, ASME, pp. 519-532, 1994.

[5] Michael, S., Use of finite element stress analysis in the design of a tank-cannonlaunched training projectile. Computers in Engineering, ASME, pp. 533-544, 1994.

[6] Lim, C.T. \& Low, Y.J., Investigating the drop impact of portable electronic products. Electronic Components Conference, pp. 1270-1274, 2002.

[7] Karppinen, J.S., Pakarinen, J., Li, J., Mattila, T.T. \& Paulasto-Krockel, M., Formation of mechanical strains in the component board of a high-end handheld product during shock impact. Proceeding of ESTC 2010, Berlin, September 13-16, 2010.

[8] Suhir, E., Nonlinear dynamic response of a printed circuit board to shock loads applied to its support contour. Journal of Electronic Packaging, Transactions of the ASME, 114(4), pp. 368-377, 1992.

[9] Alsaleem, F., Younis, M.I. \& Miles, R., An investigation into the effect of PCB motion on the dynamic response of MEMS devices under mechanical shock loads. Journal of Electronic Packaging, 130(3), pp. 031001-1-031 002-10, 2008. 
[10] Chakka, V., Trabia, M., O’Toole, B., Sridharala, S., Ladkany, S. \& Chowdhury, M., Modeling and reduction of shocks on electronic components within a projectile. International Journal of Impact Engineering, 35, pp. 1326-1338, 2008. doi: http://dx.doi. org/10.1016/j.ijimpeng.2007.07.005

[11] Amy, R.A., Aglietti, G.S. \& Richardson, G., Reliability analysis of electronic equipment subjected to shock and vibration. Shock and Vibration, 16, pp. 45-59, 2009.

[12] Cordes, J., Lee, J., Myers, T., Hader, G., Reinhardt, L., Kessler, C., Gray, N. \& Guevara, M., Statistical comparisons between qualification tests for gun-fired projectiles. Journal of Applied Mechanics, 77, pp. 1-6, 2010. doi: http://dx.doi.org/10.1115/1.4001697

[13] Cui, J., Sun, B. \& Feng, Q., Sensitivity analysis of factors influencing MEMS package reliability. Prognostics and System Health Management Conference, pp. 1-7, 24-25, 2011.

[14] Eskandarian, A., Marzougui, D. \& Bedewi, N.E., Impact finite-element analysis of slip-base sign support mechanism. Journal of Transportation Engineering, 126, pp. 143-153, 2000. doi: http://dx.doi.org/10.1061/(ASCE)0733-947X(2000)126:2(143)

[15] Kess, H.R., Rosnow, N.J. \& Sidle, B.C., Effect of bearing surface on lap joint energy dissipation. Proceedings of SPIE - The International Society for Optical Engineering, 4753, pp. 603-610, 2002.

[16] Lobitz, D.W., Gregory, D.L. \& Smallwood, D.O., Comparison of finite element predictions to measurement from Sandia Microslip Experiment. Proceedings of International Modal Analysis Conference (IMAC), 2, pp. 1388-1394, 2001.

[17] Gaul, L. \& Nitsche, R., The role of friction on mechanical joints. Applied Mechanics Reviews, 54, pp. 93-106, 2001. doi: http://dx.doi.org/10.1115/1.3097294

[18] Park, J.H., Moon, B.W., Lee, S.K. \& Min, K.W., Energy dissipation capacity of frictiontype reinforcing members installed at a transmission tower. Proceedings of the ASME Conference on Smart Materials, Adaptive Structures and Intelligent Systems, Ellicott City, MD, October 2008. doi: http://dx.doi.org/10.1115/SMASIS2008-492

[19] Wu, B., Wang, T., Xu, C. \& Xu, B., Finite element analysis of behavior of bolted flange connections under bending loading. Journal of Applied Mechanics and Materials, 26-28, pp. 1168-1171, 2010. doi: http://dx.doi.org/10.4028/www.scientific.net/ AMM.26-28.1168

[20] Augustatitis, V.K., Bucinskas, V. \& Pauza, V., Application of frequency method for defining threaded joint tightening. Diffusion and Defect Data Pt. B: Solid State Phenomena, 113, pp. 277-280, 2006. doi: http://dx.doi.org/10.4028/www.scientific.net/ $\underline{\text { SSP.113.277 }}$

[21] Duffey, T.A., Lewis, B.B. \& Bowers, S.M., Bolt preload selection for pulse-loaded vessel closure. Proceedings of the ASME - Pressure Vessels and Piping Division, 301, pp. 167-174, 1995. doi: http://dx.doi.org/10.1016/0020-7403(93)90080-E

[22] Duffey, T.A., Optimal bolt preload for dynamic loading. International Journal of Mechanical Sciences, 35, pp. 257-265, 1993.

[23] Esteban, J. \& Roggers, C.A., Energy dissipation through joints: theory and experiments. Computers and Structures, 75, pp. 347-359, 2000. doi: http://dx.doi.org/10.1016/S00457949(99)00096-6

[24] http://www.expresspcb.com/ExpressPCBHtm/SpecsStandard.htm

[25] Sridharala, S., Trabia, M., Ayyaswamy, A., O’Toole, B., Liu, Q. \& Chowdhury, M., Characterization of electronic board material properties under impact loading. 2007 ASME International Mechanical Engineering Congress and Exposition, Seattle, Washington, November 2007. 
[26] LS-DYNA version 970 keyword user's manual, Livermore Software Technology Corporation.

[27] Juvinall, R.C. \& Marshek, K.M., Fundamentals of Machine Component Design, 4th edn., Wiley, Hoboken, New Jersey, USA, 2006.

[28] http://www.mcmaster.com/\#rubber/=g80n49

[29] Lazan, B.J., Damping of Materials and Members in Structural Mechanics, Pergamon: Oxford, UK, 1968. 